\title{
Food insecurity and coping strategies among people living with HIV in Dar es Salaam, Tanzania
}

\author{
INNOCENT A. SEMALI ${ }^{*}$, TUZIE EDWIN ${ }^{2}$ and LEONARD E.G. MBOERA ${ }^{3}$ \\ ${ }^{1}$ Muhimbili University of Health and Allied Sciences, P.O. 65015, Dar es Salaam, Tanzania \\ ${ }^{2}$ Clinton Health Access Initiative, P.O. Box 7727, Dar es Salaam, Tanzania \\ ${ }^{3}$ National Institute for Medical Research, P.O. Box 9653, Dar es Salaam, Tanzania
}

\begin{abstract}
Food insecurity and malnutrition seriously impedes efforts to control HIV/AIDS in resource poor countries. This study was carried out to assess food security, and coping strategies among people living with HIV/AIDS (PLHIV) attending Care and Treatment Centre (CTC) in Dar es Salaam, Tanzania. A structured questionnaire was used to interview randomly selected adults ( $\geq 18$ years) who were HIV positive who have just been eligible for anti-retroviral treatment (ART) in a CTC or one who has started ART but not more than four weeks has elapsed. A total of 446 (females $=67.9 \%$; males $=32.1 \%$ ) people living with HIV/AIDS attending CTC were interviewed. About three quarters (73.1\%) of the respondents were $25-44$ years old and most (43.9\%) were married. Two thirds (66.7\%) of the respondents had primary school education. Seventy percent reported to have a regular income and $63.7 \%$ with a monthly income of less than US\$ 154 . More than half $(52.2 \%)$ of the respondents were food insecure. Food insecurity was similar in both males (54.6\%) and females (51.2\%). However, food insecurity was least (48.2\%) among those who were single and highest (57.7\%) among those cohabiting. Low level of food insecurity was associated with having completed primary education (Adjusted OR=0.27; 95\%CI, 0.09-0.82) and high income (>US\$154) $(\mathrm{OR}=0.10 ; 95 \% \mathrm{CI}, 0.01-0.67)$. Reporting two or less meals increased the likelihood of food insecurity (OR=4.2; 95\% CI1.7-9.8). Low frequency of meals was significantly more prevalent (18.6\%) among those $\geq 45$ years than among 35-44 years old respondents (6.7\%) ( $\mathrm{P}=0.04)$. Borrowing money $(55.8 \%)$ and taking less preferred foods $(53.3 \%)$ were the most common coping strategies. In conclusion, food insecurity is a significant problem among people living with HIV in Dar es Salaam which might significantly affect compliance to care and support. The study suggests that counselling of PLHIV before anti-retroviral treatment programmes should devise special strategies targeting those with low education, low income and low frequency of meals.
\end{abstract}

Key words: HIV, AIDS, food insecurity, coping strategies, Tanzania

\section{Introduction}

It was estimated that globally in 2007 there were 30.6-36.1 million people living with HIV and most of whom (22.5 million) were living in Sub-Saharan Africa. In the same year, the estimated number of deaths due to AIDS was 2.1 million worldwide, of which $76 \%$ occurred in SubSaharan Africa (UNAIDS/WHO, 2007). Tanzania is among the counties affected greatly by the HIV pandemic with a prevalence of $7 \%$ with 1.8 million adults and children estimated to be living with HIV and AIDS in 2004 (TACAIDS, 2004).

\footnotetext{
* Correspondence: Dr. Innocent A. Semali; Email: isemali@muhas.ac.tz/ innosemali@yahoo.com
} 
Food security is a condition whereby all people, at all times, have physical and economic access to sufficient, safe and nutritious food to meet their dietary needs and food preferences for an active and healthy life3. Food insecurity is common in developing countries. More than $60 \%$ of the food insecure people live in Sub-Saharan Africa and Asia. In Sub-Saharan Africa alone, an estimated two billion people experience food insecurity and its consequences like malnutrition and dietary deficiencies (FAO, 2003). A high proportion of households in sub-Saharan Africa are therefore in a constant process to mitigate and cope with hunger or hunger threat in addition to HIV and AIDS. In Tanzania, it is estimated that $58 \%$ of the households are having a problem meeting their food needs (TDHS, 2005) and thus their mitigation and coping strategies are seriously threatened by the high burden of HIV and AIDS and hence escalation of food insecurity.

There is a bidirectional relationship between HIV/AIDS and food insecurity. In one direction food insecurity increases the risk of HIV infection as well as fast progression to AIDS (Oxfam, 2002). Food insecurity raises risks of HIV infection as people adopt behaviours to mitigate it such as migration as cheap labour, exchange sex for money or food and loss of family ties, thus increasing their vulnerability especially among women and children (Oyefara, 2007). Due to food insecurity and resulting malnutrition among those HIV infected there is early onset of AIDS, due to an increased susceptibility to opportunistic infections. In the other direction pathway from HIV/AIDS to food insecurity is through decreased food intake, mal-absorption and increased utilization and excretion of nutrients, which in turn hasten the onset of AIDS (Semba \& Tanga, 1999). There is also early onset of opportunistic infections, reduced productivity at individual and household level, excessive demand on household resources to care for the sick and consequently inability to meet the food needs for HIV positive individual and the household (Barnett, 1994; Gillespie \& Kadiyala, 2005; Barnett \& Topouzis, 2003). Such households will have problems to meet the nutritional needs of the PLHIV which will compromise the expected benefits of anti-retroviral therapy (ART). In a recent study in Jinja, Uganda11 noted that HIV/AIDS pandemic has increased the inability of affected households to afford enough food because of the continued decrease in productivity and high expenditure on medical costs.

Currently a response to the HIV epidemic in Tanzania includes establishment of care and treatment centres (CTC) to provide free ART. It also provides nutritional counselling to make sure PLHIV and families adopt nutritional strategies to ensure compliance to ART through improved nutrition (FANTA (2004). Long term impact of HIV is limited capacity to mitigate its impact on nutrition, food security and others to the sick person and households.

Despite the knowledge of HIV/AIDS and its negative impacts on the nutritional status and individual/household food security, there is paucity of statistics on the magnitude of food insecurity and coping strategies among PLHIV on ART in Tanzania. Such information is crucial for programme planners and policy makers to provide evidence based nutritional interventions within the contexts of HIV prevention, care and treatment programmes. This study was therefore, carried out to assess food security, associated factors and coping strategies among people living with HIV who are newly enrolled at Care and Treatment Centres in Dar es Salaam, Tanzania. 


\section{Materials and Methods}

\section{Study area}

This was a cross-sectional study conducted in Dar es Salaam City, Tanzania in July-August 2008. Dar es Salaam is the largest commercial city in Tanzania, with a population estimated at 2.9 million. Administratively, the City has three municipalities (Kinondoni, Ilala and Temeke), 11 divisions, 73 wards and 276 streets. Its population growth rate is very high due to high immigrants looking for economic opportunities and thus creating conducive context of HIV transmission, hence a higher prevalence. The HIV prevalence in the City is estimated at $11 \%$ making it second leading region in the country (TACAIDS, 2004). Dar es Salaam was chosen purposeful, as it was the region with highest number of CTC in Tanzania, located mainly in the Government health facilities. At the time of this study, there were 29 CTCs in Dar es Salaam.

\section{Study subjects and sampling}

A multi-stage random sampling was used to select two CTCs from each of the Municipalities. The sample size was divided equally between the six CTC and thus 100 patients were randomly selected in each CTC. On each working day every fifth eligible patient was counselled, the objectives of the study were explained and consent to participate was then sought and only those who consented were included in to the study and interviewed in privacy.

Inclusion into the study was an HIV positive patient aged 18 years and above who has just been eligible for ART treatment in a CTC or one who has started ART but not more than four weeks has elapsed. Calculation of sample size assumed that $50 \%$ of the PLHIV were experiencing food insecurity and the true range would lie between $45 \%$ and $55 \%$. The margin of error was set at $5 \%$ with power of 90 . Minimum sample yielded by the parameters was 550 which was rounded to 600 .

\section{Data collection}

Data collection was done using a pre-tested questionnaire with closed end questions in Kiswahili. Face-to-face interviews conducted at CTCs were used to collect data on demographic and socioeconomic characteristics, income, means of accessing food, frequency of meals and how individuals coped with inadequate finance and or food.

Food security status was measured using three questions which were (i) whether or not the respondent was worried that food would run out; (ii) that the respondent had bought food but did not last and did not have money to buy more; and (iii) the respondent had to reduce the size of meals or skipped meals because there was not enough food or money to buy food. Food insecurity was defined as having any two among the three above indicators. Household socioeconomic status was determined using the stated income.

\section{Data analysis}

At the end of each day, data collected was checked for completeness and consistency and open questions were coded. The data was entered into computer using dBase IV followed by data checks and cleaning. Data cleaning was done followed by generation of frequencies and simple proportions. Data analysis was done using STATA Version 8 statistical software which included 
cross-tabulation, calculation of Odds Ratio (OR) (crude and adjusted) and its 95\% confidence interval (CI). For all statistical tests, $\mathrm{P} \leq 0.05$ was considered significant.

\section{Ethical considerations}

Ethical clearance for conducting the research was sought and obtained from the Research Ethics Committee of the Muhimbili University of Health and Allied Sciences. Permission to carry out the study was obtained from Regional, District and Health Facility authorities. The purpose of the study was explained to all and each eligible individual at the CTC and a verbal consent was sought before an interview was conducted.

\section{Results}

\section{Socio-demographic characteristics}

Of the targeted 600 people living with HIV attending CTS in the three municipalities in Dar es Salaam, only 446 provided their consent and interviewed. Of these, 153 (34.3\%) were from Ilala, 150 (33.6\%) Temeke and 143 (32.1\%) Kinondoni (Table 1). A large proportion (67.9\%) of respondents was females and about three quarters (73.1\%) were $25-44$ years old. Only 23 (5\%) of the respondents were below 25 years. Most (44.0\%) of the respondents were married. About two thirds $(66.6 \%)$ of the respondents had completed primary school education. More than half $(58.5 \%)$ were heads of households. A large proportion of the respondents reported a regular income $(70.3 \%)$.

Table 1: Socio-demographic characteristics of respondents in Dar es Salaam

\begin{tabular}{llll}
\hline Variable & Response & No. response & Per cent response \\
\hline Sex & Female & 300 & 67.9 \\
Age & Male & 143 & 32.1 \\
& $<25$ & 23 & 5.2 \\
& $25-34$ & 177 & 39.7 \\
Religion & $35-44$ & 149 & 33.4 \\
& $45+$ & 97 & 21.8 \\
Marital status & Christian & 171 & 38.3 \\
& Moslem & 275 & 61.7 \\
& Single & 83 & 18.6 \\
& Married & 196 & 44.0 \\
Education & Widowed & 67 & 15.0 \\
& Separated/Divorced & 74 & 16.6 \\
& Cohabiting & 26 & 5.8 \\
Occupation & No formal education & 53 & 11.9 \\
& Primary & 297 & 66.6 \\
Income in US\$ & Post primary & 96 & 21.5 \\
& Peasant & 44 & 9.9 \\
& Formal employment & 48 & 10.8 \\
& Informal employment & 261 & 58.5 \\
& Others & 93 & 20.9 \\
& No & 134 & 30.0
\end{tabular}




$\begin{array}{lll}<50 & 150 & 33.6 \\ 50-82.9 & 87 & 19.5 \\ 83-165.9 & 38 & 8.5 \\ 166+ & 37 & 8.3\end{array}$

\section{Household food security}

Overall, $233(51.2 \%)$ of the respondents were found be food insecure. Food insecurity was slightly more prevalent among males (54.6\%) than females, and increased with age from $43.5 \%$ among those less than 25 years to $58.8 \%$ among those 45 years and older. Food insecurity was least (48.2\%) among those who were single and highest (57.7\%) among those cohabiting (Table 2).

Table 2: Household food security status and selected characteristics

\begin{tabular}{|c|c|c|c|c|}
\hline \multirow[t]{2}{*}{ Variable } & \multirow[t]{2}{*}{ Response } & \multicolumn{3}{|c|}{ Food Security Status } \\
\hline & & Income N (\%) & Secure N (\%) & P-value \\
\hline \multirow[t]{2}{*}{ Sex } & Female & $155(51.2)$ & $148(48.8)$ & 0.503 \\
\hline & Male & $78(54.6)$ & $65(45.5)$ & \\
\hline \multirow[t]{4}{*}{ Age } & $<25$ & $10(43.5)$ & $13(56.5)$ & 0.273 \\
\hline & $25-34$ & $85(48.0)$ & $92(52.0)$ & \\
\hline & $35-44$ & $81(54.4)$ & $68(45.6)$ & \\
\hline & $45+$ & $57(58.8)$ & $40(41.3)$ & \\
\hline \multirow[t]{5}{*}{ Marital status } & Single & $40(48.2)$ & $43(51.8)$ & 0.870 \\
\hline & Married & $101(51.5)$ & $95(48.5)$ & \\
\hline & Widowed & $36(53.7)$ & $31(46.3)$ & \\
\hline & Separated/Divorced & $41(55.4)$ & $33(44.6)$ & \\
\hline & Cohabiting & $15(57.7)$ & $11(42.3)$ & \\
\hline \multirow[t]{3}{*}{ Education status } & No formal education & $35(66.0)$ & $18(34.0)$ & $<0.001$ \\
\hline & Primary & $163(54.9)$ & $134(45.1)$ & \\
\hline & Post Primary & $35(36.5)$ & $61(63.5)$ & \\
\hline \multirow[t]{4}{*}{ Occupation } & Peasant & $20(45.5)$ & $24(54.6)$ & 0.017 \\
\hline & Formal employment & $16(33.3)$ & $32(66.7)$ & \\
\hline & Informal employment & $149(57.1)$ & $112(42.9)$ & \\
\hline & Others & $48(51.6)$ & $45(48.4)$ & \\
\hline \multirow{5}{*}{ Income in US\$ } & No & $73(54.5)$ & $61(45.5)$ & $<0.001$ \\
\hline & $<50$ & $94(62.7)$ & $56(37.3)$ & \\
\hline & $50-82.5$ & $45(51.7)$ & $42(48.3)$ & \\
\hline & $83-165.9$ & $16(42.1)$ & $22(57.9)$ & \\
\hline & $166+$ & $5(13.5)$ & $32(86.5)$ & \\
\hline
\end{tabular}

Factors which were significantly associated with low likelihood of food insecurity included having completed primary education (Adjusted $\mathrm{OR}=0.27 ; 95 \% \mathrm{CI}, 0.09-0.82$ ) and high income (>US\$166) $(\mathrm{OR}=0.10 ; 95 \% \mathrm{CI}, 0.01-0.67)$. The frequency of reporting two or less meals increased the likelihood of food insecurity $(\mathrm{OR}=4.2 ; 95 \% \mathrm{CI} 1.7-9.8)$ Table 3. 
Table 3: Food insecurity adjusted for age and sex

\begin{tabular}{|c|c|c|c|c|c|}
\hline \multirow[t]{2}{*}{ Variable } & \multirow[t]{2}{*}{ Response } & \multicolumn{2}{|c|}{ Crude } & \multicolumn{2}{|c|}{ Adjusted* } \\
\hline & & OR & $95 \% \mathrm{CI}$ & OR & $95 \% \mathrm{CI}$ \\
\hline \multirow[t]{2}{*}{ Sex } & Female & 1.00 & & 1.00 & \\
\hline & Male & 1.15 & $0.77-1.71$ & 0.95 & $0.60-1.50$ \\
\hline \multirow[t]{4}{*}{ Age } & $<25$ & 1.00 & & 1.00 & \\
\hline & $25-34$ & 1.20 & $0.50-2.89$ & 1.14 & $0.47-2.79$ \\
\hline & $35-44$ & 1.55 & $0.64-3.77$ & 1.74 & $0.70-4.32$ \\
\hline & $45+$ & 1.85 & $0.73-4.69$ & 1.52 & $0.55-4.18$ \\
\hline \multirow[t]{3}{*}{ Education level } & No education & 1.00 & & 1.00 & \\
\hline & Primary & 0.63 & $0.34-1.16$ & 0.45 & $0.20-1.00$ \\
\hline & Post-primary & 0.30 & $0.14-0.62$ & 0.27 & $0.09-0.82$ \\
\hline \multirow[t]{4}{*}{ Occupation } & Peasant & 1.00 & & 1.00 & \\
\hline & Formal & 0.60 & $0.26-1.41$ & 0.40 & $0.10-1.60$ \\
\hline & Informal & 1.60 & $0.84-3.04$ & 1.35 & $0.62-2.95$ \\
\hline & Others & 1.28 & $0.62-2.64$ & 1.70 & $0.66-4.41$ \\
\hline \multirow{5}{*}{ Income } & No & 1.00 & & 1.00 & \\
\hline & $<50$ & 1.40 & $0.87-2.26$ & 1.17 & $0.68-2.00$ \\
\hline & $50-82.5$ & 0.90 & $0.52-1.54$ & 0.67 & $0.32-1.44$ \\
\hline & $83-165.8$ & 0.61 & $0.29-1.27$ & 0.31 & $0.08-1.28$ \\
\hline & $166+$ & 0.13 & $0.04-0.38$ & 0.10 & $0.01-0.67$ \\
\hline \multirow[t]{5}{*}{ Marital status } & Single & 1.00 & & 1.00 & \\
\hline & Married & 1.14 & $0.68-1.91$ & 0.99 & $0.56-1.74$ \\
\hline & Widowed & 1.25 & $0.65-2.39$ & 1.80 & $0.66-4.91$ \\
\hline & Separated/Divorced & 1.34 & $0.71-2.51$ & 1.23 & $0.42-3.57$ \\
\hline & Cohabiting & 1.47 & $0.60-3.59$ & 1.16 & $0.33-4.07$ \\
\hline \multirow[t]{2}{*}{ Meal frequency } & $3+$ & 1.00 & & 1.00 & \\
\hline & $<3$ & 4.16 & $2.05-8.43$ & 4.07 & $1.69-9.82$ \\
\hline
\end{tabular}

${ }^{*}$ Adjusted for age and sex

\section{Frequency of meals consumption}

The majority $(88 \%)$ of the respondents took three or more meals per day while the remaining took two or less meals per day (Table 4$)$. The proportion of males $(12.2 \%)$ and females $(11.9 \%)$ who took less than two meals a day was similar $(\mathrm{P}=0.922)$. Low frequency of meals was significantly more prevalent (18.6\%) among those 45 years or older compared to $6.7 \%$ among those aged $35-44$ years old $(\mathrm{P}=0.04)$. Significantly, a larger proportion $(20.8 \%)$ of those without formal education was taking two or less meals per day compared to $14.1 \%$ among those who completed primary education $(\mathrm{P}<0.001)$. 
Table 4: Comparison of meal consumption and selected characteristic

\begin{tabular}{|c|c|c|c|c|}
\hline Variable & Response & $\begin{array}{l}\leq 2 \text { meals per day } \\
N(\%)\end{array}$ & $\begin{array}{l}\geq 3 \text { meals per day } \\
\mathrm{N}(\%)\end{array}$ & P-value \\
\hline \multirow[t]{2}{*}{ Sex } & Female & $37(12.2)$ & $266(87.8)$ & 0.922 \\
\hline & Male & $17(11.9)$ & $126(88.1)$ & \\
\hline \multirow[t]{4}{*}{ Age } & $<25$ & $2(8.7)$ & $21(91.3)$ & \\
\hline & $25-34$ & $24(13.6)$ & $153(86.4)$ & \\
\hline & $35-44$ & $10(6.7)$ & $139(93.3)$ & \\
\hline & $45+$ & $18(18.6)$ & $79(81.4)$ & \\
\hline \multirow[t]{3}{*}{ Education level } & No education & $11(20.8)$ & $42(79.3)$ & $<0.001$ \\
\hline & Primary & $42(14.1)$ & $255(85.9)$ & \\
\hline & Post-primary & $1(1.0)$ & $95(99.0)$ & \\
\hline \multirow[t]{4}{*}{ Occupation } & Peasant & $8(18.2)$ & $36(81.8)$ & 0.196 \\
\hline & Formal & $2(4.2)$ & $46(95.8)$ & \\
\hline & Informal & $31(11.9)$ & $230(88.1)$ & \\
\hline & Others & $13(14.0)$ & $80(86.0)$ & \\
\hline \multirow[t]{5}{*}{ Income } & No & $22(16.4)$ & $112(83.6)$ & 0.007 \\
\hline & $<50$ & $24(16.0)$ & $126(84.0)$ & \\
\hline & $50-82.5$ & $7(8.1)$ & $80(92.0)$ & \\
\hline & $83-165.8$ & $0(0.0)$ & $38(100.0)$ & \\
\hline & $166+$ & $1(2.7)$ & $36(97.3)$ & \\
\hline \multirow[t]{5}{*}{ Marital status } & Single & $5(6.0)$ & $78(94.0)$ & 0.347 \\
\hline & Married & $24(12.2)$ & $172(87.8)$ & \\
\hline & Widowed & $11(16.4)$ & $56(83.6)$ & \\
\hline & Separated/Divorced & $10(13.5)$ & $64(86.5)$ & \\
\hline & Cohabiting & $4(15.4)$ & $22(84.6)$ & \\
\hline \multirow[t]{2}{*}{ Food security status } & Secure & $11(5.2)$ & $202(94.8)$ & $<0.001$ \\
\hline & Insecure & $43(18.5)$ & $190(81.6)$ & \\
\hline
\end{tabular}

\section{Support received and coping strategies}

Majority $(73.5 \%)$ of the respondents reported getting support from various sources; mainly from household members (72.6\%). Others sources included relatives, friends, neighbours and relief organizations (including community, faith-based and non-governmental organizations). The support included food (167), medication (302), clothes (39), moral (223), transport (57), legal (5), spiritual (66) and others (2).

Coping strategies reported included borrowing money (55.8\%), taking less preferred foods $(53.3 \%)$, taking smaller food portion (43.0\%), skipping meals (41.2\%), practicing maternal buffering (10.9\%) and selling household assets and sending children to work (1.8\%) (Table 5). 
Table 5: Source of support and coping mechanisms in response to food insecurity

\begin{tabular}{llll}
\hline Variable & Response & $\mathbf{N}$ & $\mathbf{\%}$ \\
\hline Source of support (N=328) & Household members & 238 & 72.56 \\
& Relatives & 210 & 64.02 \\
& Friends & 133 & 40.55 \\
& Neighbours & 127 & 38.72 \\
& CBO/NGO/FBO & 133 & 40.55 \\
& Others & 5 & 1.52 \\
\hline Coping strategy $(\mathrm{N}=165)$ & Response & $\mathrm{N}$ & $\%$ \\
\hline & Eating less preferred foods & 88 & 53.33 \\
& Limiting food portion size Skipping & 71 & 43.03 \\
& meals & 68 & 41.21 \\
& Borrowing food or money & 92 & 55.76 \\
& Maternal buffering & 18 & 10.91 \\
& Others & 3 & 1.82 \\
\hline
\end{tabular}

\section{Discussion}

The study revealed that more than half of the PLHIV attending CTC in Dar es Salaam was experiencing food insecurity. Food insecurity was less likely among those who had completed primary school education or those with high income. The likelihood was significantly high among those reporting two or less feeding frequencies in a day. Although the prevalence of food insecurity between male than female respondents in this study was similar, gender differences in resource control, income earning, consumption and expenditure have been identified as important factors in household's food security (Babatunde et al., 2007). Studies involving general population have shown that males were more likely to report food insecurity compared to females despite having lower resources (Vepa, 2007; Weiser et al., 2007). According to Lemke (2003), it is likely that women have better personal strategies to cope with food insecurity, often by engaging in the informal sector or social networks which enable them to support their household better. In contrary, in a recent study in Nigeria, female-headed households were found to be more vulnerable to food insecurity than the male-headed households (Babatunde et al., 2007).

In this study low income significantly increased the likelihood of food insecurity among PLHIV. The main means of accessing food among PLHIV in Dar es Salaam is through purchase. Thus the amount of food made available to PLHIV or respective household is a direct reflection of its purchasing power. Thus with the existing high poverty which preceded the HIV/AIDS epidemic those with low income or lacked income are not able to afford adequate food and therefore are food insecure.

Several studies have already demonstrated links between HIV/AIDS and household food insecurity (UNAIDS, 2003). The relationship of food insecurity and low income found among PLHIV in this study could also be a result of HIV/AIDS. This is because frequent illness including opportunistic infections cause significant disability leading to reduced productivity, depletion of savings and inability to earn more incomes (Gari, 2002). Studies in India have also 
shown that affected households face severe constraints due to poor health that lead to reduced income and increased health expenditure (Basu et al., 1997; Gupta, 1998). In Malawi, it has been reported that $70 \%$ of the households affected by chronic sickness, suffered from labour shortage (Shah et al., 2001). Other studies in Tanzania, Cote d'Ivoire and South Africa have indicated that HIV/AIDS afflicted households tend to incur high medical care expenditures (Tibaijuka, 1997; Bechu, 1998; Booysen et al., 2004). This indicates that HIV/AIDS could lead to food insecurity through diminished earning of an individual or household.

Low level of education of the respondents was an important factor influencing food insufficient among the PLHIV in Dar es Salaam. General population as well as PLHIV with higher education are more likely to be employed and thus get paid on regular basis or will be paid a much higher wage. On the other hand highly educated people are more likely to generate better income from income generating activities. Furthermore low education is also associated with higher likelihood of HIV as well as poverty which is also associated with food insecurity. Thus because of low education and hence low income, PLHIV are unable to afford the right quantity and quality of food leading to food insecurity. The association between low education and food insecurity among PLHIV has also been reported in a study in Malawi (Palamuleni et al., 2003).

The findings of this study show significant relationship between low frequency of meals in a day and food insecurity. Ensuring that a PLHIV feeding pattern observes the desired feeding frequency and quality is crucial in the care of any PLHIV. On the event that the income is low households/individuals are more likely to overstretch the little food available so that all are reached or the day is covered. Limited income will thus lead to smaller meals initially and if it persists it will eventually reduce the frequency. At the same time low feeding frequency or low quantity feed could reflect ignorance or cultural practices in a given area.

Given the existing HIV epidemic and the high level of food insecurity makes the PLHIV more vulnerable thus compromising their health because of the inability to respond to their food needs. Feeding needs are reflected in the changes in metabolism occurring due to HIV infection, cause the need for increased amount of food intake and hence increased number of meals per day (Piwoz \& Preble, 2000). Due to increased nutrient requirements, it is recommended that PLHIV consume three meals with snack each day (Kinabo et al., 2003). Despite such recommendations, a reasonable proportion of the respondents in this study reported consuming less than three meals per day indicating that many of them are in the process of mitigating the existing food insecurity. This further suggests that while screening PLHIV for CTC, information of underweight due to both fewer number of meals and disease process should be monitored. Studies elsewhere have shown that people living with HIV/AIDS in resource-limited settings are often unable to follow optimal food and nutrition recommendations for ARV due to limited access to the foods required (Castleman et al., 2003). Like elsewhere, due to food insecurity, there were changes in food consumption behaviour in terms of quantity and quality (van Liere, 2002). The dietary strategies observed in this study included eating less preferred foods, reducing portion sizes served to household members, reducing the number of meals taken per day, maternal buffering and eating at neighbour's house. Non-dietary strategies included selling of critical assets and borrowing money or food. Similarly, in a recent study in Uganda, households that had low food security scores reported 
reducing household size to cut down on food costs and selling off non-productive household assets to buy food (Bukusuba et al., 2007).

Most of the identified various dietary and non-dietary coping strategies used by households during food shortages have negative repercussions on nutritional status of the PLHIV and the rest of the household members (Kraak et al., 1999). Reducing food consumption quantity and quality among PLHIV may be a highly erosive coping strategy, as nutrient requirements rise following HIV infection (Gillespie \& Kadiyala, 2005). Although some strategies are easy to recover, others are relatively difficult and may exacerbate poverty, food insecurity and malnutrition (Maxwell \& Frankenberger, 2002).

A larger proportion of PLHIV in this study reported getting assistance from household members, relatives, friends or relief organizations. However, these are considered to be unreliable sources of food (Bonnard, 2003), as such assistances are likely to be inadequate to mitigate the situation. More importantly, there was no evidence that the food assistance was targeting the most vulnerable groups which included those with low education, poor income or food insecure. This calls for a study to analyze the extent assistance provided targeted to most vulnerable among the PLHIV.

This study had a number of limitations. The study subjects were those attending CTC, which is likely not a representative of the general population of PLHIV. Moreover, there are possibilities that the responses of the study subjects were biased. The responses as regards to reduced income and ability to access food as well eating frequency might have been prompted by the expectations of receiving food support from the researchers. However, this limitation was overcome by explaining the objective of the study to the subjects. This was a cross-sectional study, it was therefore, difficult to determine whether food insecurity was seasonal or not. A longitudinal community-based study to cover for both urban and rural settings is recommended for future research.

The study findings indicate that food insecurity was a significant problem among PLHIV attending CTC in Dar es Salaam. Food insecurity was significantly associated with low education and income leading to consumption of fewer meals a day. Strategies to address food security among PLHIV should be high on the national and district agenda to care and support them. The strategies should aim at increasing food access in terms of quantity, quality, and timing to PLHIV. Such efforts require targeting to make them efficient and effective thus ensuring compliance to ART. The targeting strategy should focus on those with low education, low income and low feeding frequency. It calls for impartial screening with minimal intrusiveness to understand PLHIV who would benefit from such targeting programmes.

\section{Competing interests}

No competing interests

\section{Authors' contributions}

Tuzie Edwin conceived the idea and participated in field data collection. Innocent Semali contributed to the design of the research method. Leonard Mboera contributed to the 
conception of the idea and development of the proposal. Both authors collaborated on the final analysis and manuscript preparation.

\section{Acknowledgements}

We would like to thank Jacqueline Stanley, Faraja Ndulesi, Dotto Francis and Happy Nkunda for their excellent field assistance during data collection. I owe debt of gratitude to all interviewees for their enthusiasm and willingness to participate in the study. We are grateful to Rodgers Rindeni for data entry and cleaning and to Kesheni Senkoro, Filemoni Tenu and Thomas Mwenyeheri for data analysis. This research received financial assistance from Muhimbili University of Health and Allied Sciences and Belgian Technical Cooperation.

\section{References}

Babatunde, R.O., Owotoki, G.M., Heidhues, F. \& Buchenrieder, G. (2007) Vulnerability and food insecurity differentials among male and female-headed farming households in Nigeria. Pakistan Journal of Social Sciences 4, 414-418.

Barnett, T. \& Topouzis, D. (2003) FAO and HIVIAIDS: towards a food and livelihoods security based strategic response. Rome: Sustainable Development Department, Food and Agriculture Organization.

Barnett, T. (1994) The effects of HIVIAIDS on farming systems and rural livelihoods in Uganda, Tanzania and Zambia. FAO project TSS/1 RAF/92/TO/A. Food and Agriculture Organization 164-279.

Basu, A., Gupta, D.B. \& Krishna, G. (1997) The household impact of adult mortality, morbidity, and mortality: Some implications of the potential epidemic of AIDS in India. In: D.E. Bloom \& P. Godwin (ed). The economics of HIV and AIDS: The case of south and southeast Asia. Delhi: Oxford University Press, 1997.

Bechu, N. (1998) The impact of AIDS on the economy of families in Côte d'Ivoire: Changes in consumption among AIDS-affected households. In: M. Ainsworth, L. Fransen \& M.Over (eds). Confronting AIDS: Evidence from the Developing World. European Commission and AIDS Analysis in Africa 1998; 8(1), 2-3.

Bonnard, P. (2003) Food Security programming in HIVIAIDS Contexts. FANTA/ USAID. Washington. DC. 2003, 22 pp.

Booysen, F., Bachmann, M., Matabesi, Z. \& Meyer, J. (2004) The Socio-Economic Impact of HIVIAIDS on Households in South Africa: Pilot Study in Welkom and Qwaqwa, Free State Province. University of the Free State, Centre for Health Systems Research and Development \& South Africa Joint Economics AIDS and Poverty Program. Available at: http://www.jeapp.org.za/article.php?cat=allresearch_id=7.

Bukusuba, J., Kikafunda, J.K. \& Whitehead, R.G. (2007) Food security status in households of people living with HIV/AIDS (PLWHA) in a Ugandan urban setting. British Journal of Nutrition 98, 211-217. 
Castleman, T., Seumo-Fosso, E. \& Cogill, B. (2003) Food and Nutrition Implications of Antiretroviral Therapy in Resource Limited Settings. Washington DC: Food and Nutrition Technical Assistance, Academy for Educational Development.

FANTA (2004) HIVIAIDS: A Guide For Nutritional Care And Support. Food and Nutrition Technical Assistance (FANTA) Project. Academy for Educational Development, Washington DC, 2004.

FAO (2003) The State Of Food Insecurity In the World. Food and Agriculture Organization, Rome. Gari, J.A. (2002) Agro-biodiversity, food security and HIV/AIDS mitigation in Sub-Saharan Africa. Strategic Issues for Agricultural Policy and Programme Responses. FAO, Rome Italy.

Gillespie, S. \& Kadiyala, S. (2005) HIVIAIDS and Food and Nutrition Security, From Evidence to Action. Food Policy Review 7. International Food Policy Research Institute. Washington DC. 194.

Gupta, I. (1998) Planning for the socioeconomic impact of the epidemic: The costs of being ill. In P. Godwin (ed): The looming epidemic: The impact of HIVIAIDS in India, ed. P. Godwin. Delhi.

Kinabo, J., Mnkeni, A., Nyaruhucha, C.N.M., Msuya, J. \& Ishengoma, J. (2003) Nutrients content of foods commonly consumed in Iringa and Morogoro Regions. Proceedings of the 2nd Collaborative Research Workshop on Food Security, TARP II SUA Project held in Morogoro, 28 -30th May 2003.

Kraak, V.I., Pelletier, D.L., Frongillo, E.A. \& Rajabiun. S. (1999) The Potential Role of Food Aid for AIDS Mitigation in East Africa: Stakeholders Views. Washington: FANTA, 1999.

Lemke, S. (2003) Empowered women and the need to empower men: gender relations and food security in black South African households. Studies of Tribes and Tribals 1(1), 59-67.

Maxwell, S. \& Frankenberger, T. (2002) Household food security: Concepts, Indicators, measurements. A technical review. UNICEF, New York, USA, 2002.

Oxfam (2002) Save the Children and Oxfam: HIV/AIDS and Food Security, 2002. (www.oxfam.org/en/files/pp0121127-aids-safrica.pdf )

Oyefara, J.L. (2007) Food insecurity, HIV/AIDS pandemic and sexual behaviour of female commercial sex workers in Lagos metropolis, Nigeria. Journal of Social Aspects of HIVIAIDS 4, 626-635.

Palamuleni, M.E., Kambewa, P.S., Kadzandira. J. (2003) Impact of HIV/AIDS on Food Security: the case of affected and infected urban households in Malawi. Food Africa, 5 - 9 May 2003.

Piwoz, E.G. \& Preble, E.A. (2000) HIVIAIDS and Nutrition: A Review of the Literature and Recommendations for Nutritional Care and Support in Sub Saharan Africa.

Semba, R.D. \& Tang, A.M. (1999) Micronutrients and the pathogenesis of human immunodeficiency virus infection. British Journal of Nutrition 81, 181-189.

Shah, M.K., Osborne, N., Mbilizi, T. \& Vilili, G. (2001) Impact of HIV/AIDS on agricultural productivity and rural livelihoods in the Central Region of Malawi. CARE International, Malawi, 2001.

TACAIDS (2004) Tanzania Commission for AIDS. National Bureau of Statistics (NBS) and ORC Macro. Calverton, Maryland, USA: TACAIDS, NBS, and ORC Macro. 
TDHS (2005) Tanzania HIVIAIDS Indicator Survey 2003-04. Tanzania Demographic and Health Survey. Macro International and National Bureau of Statistics. United Republic of Tanzania, 2005.

Tibaijuka, A.K. (1997) AIDS and Economic Welfare in Peasant Agriculture: case Studies from Kagabiro Village, Kagera Region, Tanzania. World Development 25, 963-975.

UNAIDS (2003) Report on the Global HIVIAIDS Epidemic. UNAIDS, Geneva.

UNAIDS/WHO (2007) Report on the Global AIDS Epidemic, 2007. [http://www.webcare.md/] van Liere, M.J. (2002) HIVIAIDS and Food Security in sub-Saharan Africa. Royal Tropical Institute, the Netherlands.

Vepa, S.S. (2007) Gender equity and human development. Indian Journal of Medical Research 126, 328-340.

Weiser, S.D., Leiter, K., Bangsberg, D.R., Butler, L.M., Percy-de Korte, F., Hlanze, Z., Phaladze, N., Iacopino, V. \& Heisler, M. (2007) Food insufficiency is associated with high risk sexual behavior among women in Botswana and Swaziland. PLoS Medicine 4 (10): e260. doi:10.1371/journal.pmed.0040260. 